\title{
Information and the Transformation of Sociology: Inter- activity and Social Media Monitoring
}

\author{
Hugh Mackay
}

\author{
The Open University, Milton Keynes, UK, A.H.Mackay@Open.ac.uk, \\ http:// www.open.ac. uk/ socialsciences/ staff/ people-profile. php?name=Hugh Mackay
}

\begin{abstract}
This paper explores some key ways in which the scale and form of information today challenges some of sociology's core methods and practice. Information has shaped sociology in two key ways. First, it has become an object of study, largely in the form of accounts of the epochal shift to 'the information society'. This paper examines interactivity as a key element of such changes, especially in relation to the mass media. The second way in which sociology is being transformed by the growth of information is that, with the growth of huge volumes of commercial transactional information, social data is no longer the preserve of sociologists. Moreover, new tools have emerged to challenge the research methods that lie at the heart of sociology. This paper explores this argument, originally developed by Savage and Burrows, in relation to the BBC World Service's use of social media monitoring tools. It examines some implications of the growth of interactivity, and the associated new forms of data and new research tools, to explore some key implications of information for the practice of sociology today. It concludes that the vast amount of available information affords new possibilities for sociologists as well as for the organisations that collect it, but that this requires sociologists to develop new tools and practices.
\end{abstract}

Keywords: information society; interactivity; social media monitoring; BBC World Service; social life of methods

Acknowledgement: This is based on a paper presented at the 'Difference That Makes a Difference' Workshop at The Open University, Milton Keynes, September 2011. Thanks to the participants in that workshop and to two anonymous reviewers for Triple $\mathrm{C}$ for their ideas and comments. The paper draws on research undertaken at the BBC World Service as part of a UK Arts \& Humanities Research Council Public Policy Fellowship, led by Marie Gillespie. Thanks to the many staff at the BBC's Bush House, and especially Anne Barnsdale in Audience Insights, who gave so much time and support to this project.

This paper explores some important consequences of the changing volumes and characteristics of information for the social sciences, and for sociology in particular.

The main way in which 'information' has shaped or been taken on board by sociology is in work on the 'information society'. This perhaps started with Daniel Bell's post industrial society thesis, which highlighted the decline of extractive and more recently manufacturing sectors, and the growth of the service sector, in advanced industrial economies (Bell 1974). Writers in this loosely defined field have examined the restructuring of work, the transformation of domestic life, the growing inter-dependence of economies, the increasing rate and volume of cultural circulation, new possibilities for political campaigning and engagement, and the growth of surveillance. One does not have to subscribe to notions of epochal shift (from, say, an industrial to an information or network society) to see how information is transforming social organisation across many of the realms of social life that are the focus of the work of social scientists (For a summary of this literature and these debates, see Webster 1995).

One key issue in the debate is when quantitative change (for example regarding flows of information or the level of global trade) represents qualitative change (a new form of society) - which is the subject of considerable debate and many of the critiques of the 'information society' thesis or field. In any case, information is seen by many as lying at the heart of contemporary social transformation and organisation.

Perhaps the most recent and comprehensive work in this tradition is that of Manuel Castells on the "information age" (Castells 1996; 1997; 1998). Castells argues that we now live in the "network society", which is a result of the "informational mode of development", in which information processing is at the core. For him, the "informational society" concerns the "specific form of social organization in which information generation, processing and trans-mission become the fundamental sources of productivity and power, because of new technological conditions" (Castells 1996, 21 fn33).

He argues that the network society, organised around new forms of time and space, is the dominant social structure of the information age (Castells 1999, 405). He sees places as overlaid 
by flows, which for Castells' take on a life of their own as the main source of power, and allow interests to interconnect at the nodes of networks.

\section{The Importance of Interactivity}

Castells refers to the interactivity of networks coming to bypass vertical channels of communication. With customer feedback, organisational structures and communications are being re-shaped. With participatory web-based organisations like Avaaz ${ }^{1}$ and openDemocracy ${ }^{2}$, new ways of democratic engagement and political lobbying are facilitated. And with social media we are seeing new forms of cultural production, with users increasingly involved in creating as well as consuming content (Jenkins 2006).

Fan communities are playing a role in the design of products such as Lego; computer game players develop and modify games; and plots for television dramas are shaped by viewers' ideas and preferences (Jenkins 2006). In these and numerous similar instances we can see how users are shaping technologies (Oudshoorn and Pinch 2003) and user engagement is becoming more complex and elaborate. It is significant in terms of power that these forms of cultural production are more collaborative, participatory and open: anyone can be seen and heard (Hartley 2005).

Social media are a key and prominent element of this phenomenon. They allow one to create, collaborate, share and publish content including text, audio and video (Bruns 2006). They mean that the media become more immediate, more personal and more individual. For many this is seen as progressive: centralised cultural production controlled by the few is being replaced by peer-topeer, decentralised, collaborative production (Uricchio 2004, 86). Referring to "commons-based peer production", Benkler argues that "the networked environment makes possible a new modality of organizing production: radically decentralized, collaborative and non-proprietary; based on sharing resources and outputs among widely distributed, loosely connected individuals who cooperate with each other without relying on either market signals or managerial commands" (Benkler 2006, $60)$.

A blog shifts from something like a diary for friends to a media outlet, as if one's phone has been transformed into a radio (Shirky 2008). In contrast with the one-to-many model that has characterised the institutionalisation of broadcasting (Williams 1974) and the press, news production includes both citizen journalism and the use of user generated content (UGC) by traditional media organisations. A flow of clips from mobile phones and camcorders is being used as content in programmes and services. During the Egyptian Revolution of 2011, for example, Al Jazeera handed out mobile phones in Cairo and set up a website for uploading images. Thus audiences are being engaged in new ways - in gathering, selecting, editing, producing and communicating news.

This is not merely a new source for news, it is also more interactive (for example responding to blog posts). Reconfiguring the boundary between public and private, it makes media use more like a conversation - something more immediate, more personal and more individual.

As I discuss below, there is of course a rather different perspective on this: that whilst there is more information circulating, there are fewer journalists checking sources and providing balanced accounts or informed analysis. And the Leveson Inquiry in the UK shows how the growing concentration of media ownership and control has had huge consequences for so many areas of public life.

\section{The Challenge to Sociology of Commercial and Real-Time Data Gathering}

There is, however, more to the implications of information for sociology than the new flows of information and the associated new social and cultural formations. The abundance of information that is routinely collected, processed and distributed today is so vast, relative to that which social scientists could or can gather, that it represents a challenge to the discipline itself.

By way of example, there is considerable debate in Wales about the integrity or distinctiveness of the nation and the porosity of its borders - as one would expect in a small nation that struggles to assert and construct a national identity when adjacent to such a powerful neighbour, England. Social scientists of various hues have studied this over the years. But $\mathrm{BT}^{3}$ routinely collects realtime data about the places to which people in Wales telephone - which can be seen as something of a proxy for the integrity of the nation and the significance of its boundaries. Such data is collected automatically and routinely by large commercial organisations; but it is not something to

\footnotetext{
${ }^{1}$ http://www.avaaz.org/ Accessed September 14, 2012

2 http://www.opendemocracy.net/ Accessed September 14, 2012

${ }_{3}^{3}$ BT is the UK's largest telecommunications provider, privatised from government ownership in 1984
} 
which academics enjoy access. Similarly, Amazon does not have to rely on sample surveys to work out what you might be reading. Like many other commercial organisations, it knows, or can reliably infer, your preferences and can then send targeted marketing material. They know exactly what you buy and read and what others like you are buying, hence their annoying but useful messages on their website and in their emails. Similarly with supermarkets: from the data gathered from their loyalty cards, they know more, and with remarkable granularity, about consumption behaviour in relation to geography (postcodes) than could social scientists.

This is part of the argument developed by Mike Savage and Roger Burrows in an influential paper entitled "The coming crisis of empirical sociology" published in 2007 in Sociology, the journal of the British Sociological Association. Savage and Burrows (2007) argue that in an era of knowing capitalism, the tools that were developed and deployed by sociologists, notably the sample survey and the in-depth interview, are relatively less significant. The knowledge and ownership of the tools that characterised sociology during the second half of the twentieth century allowed sociologists to claim distinctive expertise which gave them access to ways of understanding the social. Today, such claims are challenged by the growth of commercial, transactional, real-time information, which in turn has given rise to new categories and systems of social analysis.

The sort of things they are referring to are Mosaic, Experian's geo-demographic segmentation system; and CACl's ACORN system - both developed by Professor Richard Webber in the 1980s. Although both Experian and $\mathrm{CACl}$ are UK companies, the system has been exported to continental Europe, North America, the Far East and Australia. In the USA, there are similar systems: the PRIZM system from Claritas (later acquired by Nielsen) was developed by Jonathan Robbin in the 1950s and 1960s. In both cases the development was by scholars who left the academy to become entrepreneurs.

At the heart of ACORN and Mosaic are postcodes, of which there are $1.7 \mathrm{~m}$ in the UK, each covering an area including an average of 14 households. Using these, neighbourhoods are classified, as shown in Figure 1 below.

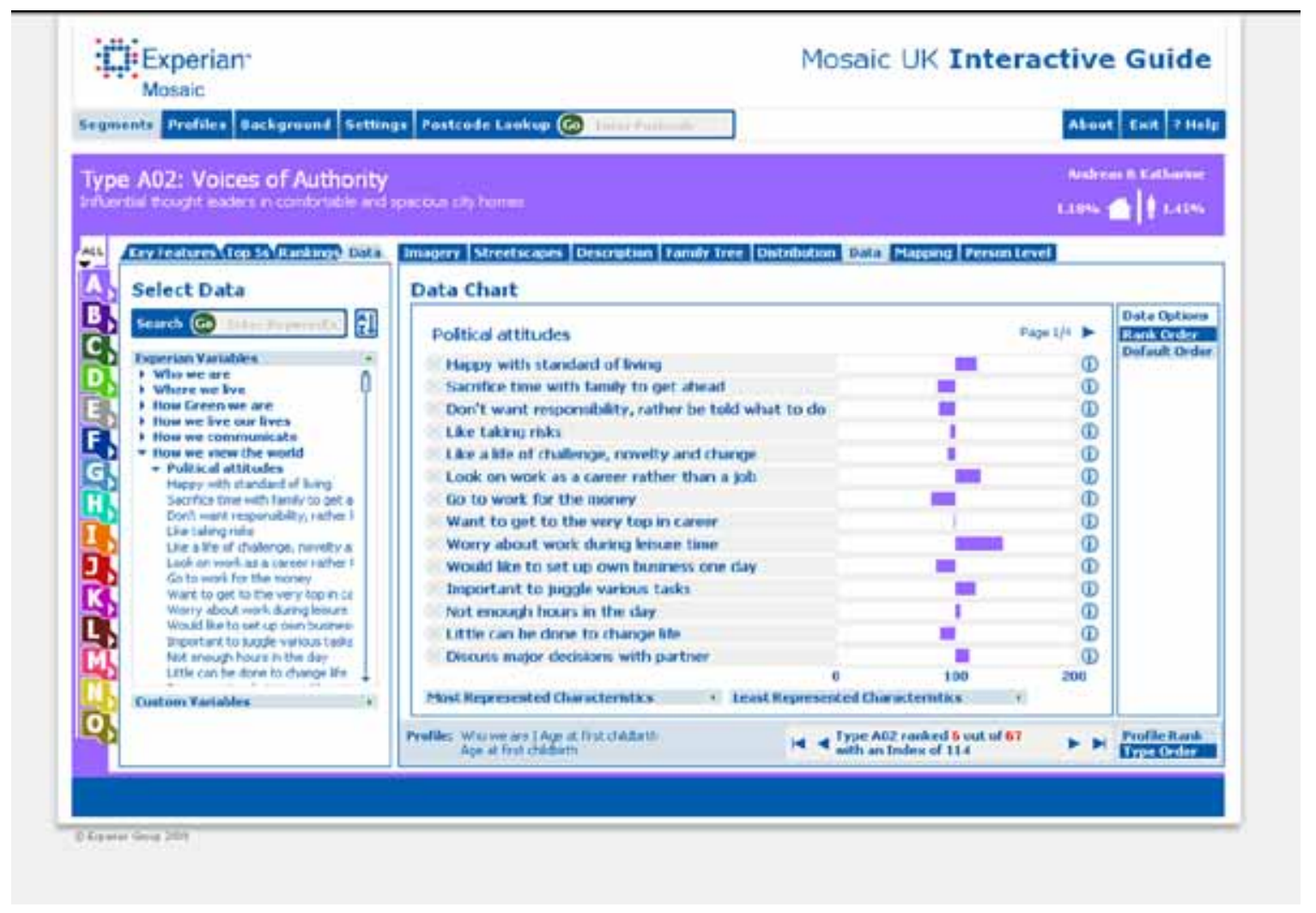

Figure 1: Mosaic "Type A02, Voices of Authority". How we view the world

Mosaic's 2009 system classifies the UK into 15 main socio-economic groups and, within these, develops a 67-fold typology (see Table 1); with each postcode assigned a Mosaic type. Typically, Mosaic uses 400 variables to arrive at its classification. About half of this data comes from the de- 
cennial census; but to this are added consumer credit databases, the Electoral Roll, shareholder registers, Council Tax information, the British Crime Survey, etc.

This classification is based on the clichés that recur in the industry, that 'birds of a feather flock together' and 'you are where you live'. Nonetheless, these systems have enormous utility for understanding consumption behaviour, since "knowledge of where someone lives is a particularly powerful predictor of all manner of consumption practices, values, tastes, preferences and so on" (Burrows and Gane 2006, 795).

Geo-demographic classifications represent a collapsing of core sociological variables (income, stage in the life cycle, race, religion, health, illness, level of educational attainment etc). Crucially, they are categorisations of the population based not on production, occupation, income or wealth; but on differences in consumption, lifestyle and cultural values. They conflate notions of class and status (Burrows and Gane 2006).

These systems are not without their critics. The algorithms, for example, are proprietary - so it is not possible to know how the categories that are the basis of the analysis are generated. Everyone in a postcode area is classified in the same way. And where a postcode is on the boundary of two possible classifications, one person's minor preference (say for lager over wine) could swing the classification of the area.

But whatever their limitations, these systems have been found to have enormous explanatory use, and have been highly influential. Although developed as marketing tools, they are now used more broadly, for example by government bodies for planning and delivering services; by insurance companies and pension funds, for example to assess longevity for pricing, thus shaping insurance premiums; by developers and retailers to choose where to open stores; or, by using call-line identification (CLI) queuing systems at call centres, to determine how quickly your telephone call is answered by a call centre (Burrows and Gane 2006).

One of the best-known applications of this system is dunnhumby's work for Tesco, the UK's largest supermarket chain. Dunn and Humby both worked for $\mathrm{CACl}$, developers of the ACORN system, prior to founding their own company, which is now owned by Tesco. They came up with the idea of the Clubcard, whereby consumers accumulate points that can be used to buy other goods; whilst the supermarket gathers data on the individual's consumer preferences, location and lifestyle. The Clubcard has been attributed with making Tesco the largest supermarket chain in the UK. When first presenting his ideas to the Managing Director of Tesco, the latter replied: "what scares me about this is that you know more about my customers after three months than I know after 30 years" (Brown 2010)

With its Clubcard data, Tesco can map consumption patterns onto postcodes, in real-time, allowing far more elaborate, up-to-date and granular categorisations of the population than facilitated by, for example, the decennial census. In relation to the mass media, the UK regulator of communications, Ofcom, has a website with research data on telecommunications and broadcasting that far exceeds that which has been or could conceivably be generated by academics. The data gathered routinely by Google or Facebook are other examples.

Not only is information increasingly prolific but also the software that facilitates its circulation and processing has come to take on a growing significance or power. Classification systems (Bowker and Star 1999) and the software within which information is embedded are becoming increasingly significant for sociological analysis. Software is intervening in nearly every aspect of social life (Thrift and French 2002, 309), shaping culture and identities. It is judging "people's worth, eligibility and levels of access to a whole range of essential ... spaces and services" (Graham 2004, 324). Data and technology have always been used to order populations, but now this is done much more than ever before, with vast, inter-linked databases and huge processing power, and often in real-time. Thus information comes to order social lives as does the physical environment, natural or constructed. Geo-demographic classifications are a significant component of this. The information and software are not simply for commercial organisations and policy-makers to deliver goods and services; but are themselves patterning social space - they have become crucial agents by, for example, determining credit ratings. They are a major reason why place has become an identifier, possibly the crucial identifier, of who you are (Savage et al. 2005, 207). 


\begin{tabular}{|c|c|c|c|c|c|c|c|}
\hline Group & Description & $\begin{array}{l}\% \\
\text { indivs }\end{array}$ & $\begin{array}{l}\% \\
\text { households }\end{array}$ & Type & Description & $\begin{array}{l}\% \\
\text { indivs }\end{array}$ & $\begin{array}{l}\text { \% } \\
\text { households }\end{array}$ \\
\hline \multirow[t]{4}{*}{ A } & \multirow[t]{4}{*}{ Alpha Territory } & \multirow[t]{4}{*}{4.28} & \multirow[t]{4}{*}{3.54} & A01 & Global Power Brokers & 0.32 & 0.30 \\
\hline & & & & $\mathrm{A} 02$ & Voices of Authority & 1.45 & 1.18 \\
\hline & & & & A03 & Business Class & 1.83 & 1.50 \\
\hline & & & & A04 & Serious Money & 0.68 & 0.56 \\
\hline \multirow[t]{6}{*}{ B } & \multirow[t]{6}{*}{ Professional Rewards } & \multirow[t]{6}{*}{9.54} & \multirow[t]{6}{*}{8.23} & B05 & Mid-Career Climbers & 2.90 & 2.30 \\
\hline & & & & B06 & Yesterday's Captains & 1.80 & 1.84 \\
\hline & & & & B07 & Distinctive Success & 0.48 & 0.48 \\
\hline & & & & B08 & Dormitory Villagers & 1.81 & 1.29 \\
\hline & & & & B09 & Escape to the Country & 1.41 & 1.31 \\
\hline & & & & B10 & Parish Guardians & 1.14 & 1.00 \\
\hline \multirow[t]{5}{*}{$\mathrm{C}$} & \multirow{5}{*}{ Rural Solitude } & \multirow[t]{5}{*}{4.84} & 4.40 & C11 & Squire Among Locals & 1.01 & 0.85 \\
\hline & & & & C12 & Country Loving Elders & 1.32 & 1.31 \\
\hline & & & & C13 & Modern Agribusiness & 1.61 & 1.36 \\
\hline & & & & C14 & Farming Today & 0.53 & 0.53 \\
\hline & & & & C15 & Upland Struggle & 0.36 & 0.34 \\
\hline $\mathrm{D}$ & Small Town Diversity & 9.21 & 8.75 & D16 & Side Street Singles & 1.21 & 1.17 \\
\hline & & & & D17 & Jacks of All Trades & 2.60 & 1.99 \\
\hline & & & & D18 & Hardworking Families & 2.87 & 2.63 \\
\hline & & & & D19 & Innate Conservatives & 2.53 & 2.96 \\
\hline$E$ & Active Retirement & 3.41 & 4.34 & E20 & Golden Retirement & 0.52 & 0.67 \\
\hline & & & & E21 & Bungalow Quietude & 1.42 & 1.79 \\
\hline & & & & E22 & Beachcombers & 0.57 & 0.60 \\
\hline & & & & E23 & Balcony Downsizers & 0.90 & 1.29 \\
\hline $\mathrm{F}$ & Suburban Mindsets & 13.16 & 11.18 & F24 & Garden Suburbia & 2.82 & 2.14 \\
\hline & & & & F25 & Production Managers & 2.31 & 2.63 \\
\hline & & & & F26 & Mid-Market Families & 3.75 & 2.70 \\
\hline & & & & F27 & Shop Floor Affluence & 2.82 & 2.73 \\
\hline & & & & F28 & Asian Attainment & 1.45 & 0.98 \\
\hline G & Careers and Kids & 5.34 & 5.78 & G29 & Footloose Managers & 1.11 & 1.67 \\
\hline & & & & G30 & Soccer Dads and Mums & 1.34 & 1.34 \\
\hline & & & & G31 & Domestic Comfort & 1.24 & 1.09 \\
\hline & & & & G32 & Childcare Years & 1.46 & 1.52 \\
\hline & & & & G33 & Military Dependents & 0.19 & 0.17 \\
\hline $\mathrm{H}$ & New Homemakers & 3.99 & 5.91 & $\mathrm{H} 34$ & Buy-to-Let Territory & 1.08 & 1.79 \\
\hline & & & & H35 & Brownfield Pioneers & 1.13 & 1.38 \\
\hline & & & & $\mathrm{H} 36$ & Foot on the Ladder & 1.48 & 2.37 \\
\hline & & & & H37 & First to Move In & 0.30 & 0.37 \\
\hline I & Ex-Council Community & 10.60 & 8.67 & 138 & Settled Ex-Tenants & 2.08 & 2.06 \\
\hline & & & & 139 & Choice Right to Buy & 1.90 & 1.72 \\
\hline & & & & 140 & Legacy of Labour & 3.46 & 2.68 \\
\hline & & & & 141 & Stressed Borrowers & 3.15 & 2.20 \\
\hline $\mathrm{J}$ & Claimant Cultures & 4.52 & 5.16 & $\mathrm{~J} 42$ & Worn-Out Workers & 1.82 & 2.30 \\
\hline & & & & $\mathrm{J} 43$ & Streetwise Kids & 0.90 & 1.05 \\
\hline & & & & $\mathrm{J} 44$ & New Parents in Need & 1.80 & 1.80 \\
\hline $\mathrm{K}$ & Upper Floor Living & 4.30 & 5.18 & K45 & Small Block Singles & 1.26 & 1.77 \\
\hline & & & & K46 & Tenement Living & 0.62 & 0.80 \\
\hline & & & & K47 & Deprived View & 0.36 & 0.50 \\
\hline & & & & K48 & Multicultural Towers & 1.09 & 1.11 \\
\hline & & & & K49 & Re-Housed Migrants & 0.97 & 0.99 \\
\hline $\mathrm{L}$ & Elderly Needs & 4.04 & 5.96 & L50 & Pensioners in Blocks & 0.89 & 1.31 \\
\hline & & & & L51 & Sheltered Seniors & 0.67 & 1.12 \\
\hline & & & & L52 & Meals on Wheels & 0.51 & 0.86 \\
\hline & & & & L53 & Low Spending Elders & 1.98 & 2.68 \\
\hline M & Industrial Heritage & 7.39 & 7.40 & M54 & Clocking Off & 2.18 & 2.25 \\
\hline & & & & M55 & Backyard Regeneration & 2.40 & 2.06 \\
\hline & & & & M56 & Small Wage Owners & 2.81 & 3.09 \\
\hline $\mathrm{N}$ & Terraced Melting Pot & 6.54 & 7.02 & N57 & Back-to-Back Basics & 2.50 & 1.97 \\
\hline & & & & N58 & Asian Identities & 1.06 & 0.88 \\
\hline & & & & N59 & Low-Key Starters & 1.60 & 2.72 \\
\hline & & & & N60 & Global Fusion & 1.38 & 1.44 \\
\hline $\mathrm{O}$ & Liberal Opinions & 8.84 & 8.48 & $\mathrm{O61}$ & Convivial Homeowners & 1.74 & 1.68 \\
\hline & & & & $\mathrm{O} 62$ & Crash Pad Professionals & 1.41 & 1.09 \\
\hline & & & & $\mathrm{O} 63$ & Urban Cool & 1.25 & 1.10 \\
\hline & & & & 064 & Bright Young Things & 1.36 & 1.52 \\
\hline & & & & 065 & Anti-Materialists & 1.12 & 1.03 \\
\hline & & & & O66 & University Fringe & 1.10 & 0.93 \\
\hline & & & & $\mathrm{O} 67$ & Study Buddies & 0.87 & 1.14 \\
\hline
\end{tabular}

Table 1. Mosaic's classification of consumers in the UK (adapted from Experian 2010) 
It is a short step from seeing information and software as social agents to understanding that social research tools and methods, rather than merely measuring some objective social reality 'out there', can be seen as playing a part in constructing it (Law et al. 2011). More than this, we can see these tools and methods as a challenge to social science, due to the ownership of both the tools (e.g. algorithms) of measurement and the data. No longer do these 'belong' to academic sociologists. As an aside, commercial organisations operate relatively unencumbered by the growing plethora of ethics regulation that characterises research conducted by universities.

\section{Real-Time Data on Interactivity and Social Media at the BBC World Service}

I now connect these ideas with interactivity in 'the information society'. New media, with the interactivity that they afford, are transforming the one-to-many model of the press and broadcasting. Interactivity changes fundamentally the relationship of a broadcaster with its audience - which has become more fluid and dynamic. Authority is challenged, the power of traditional media organisations is diminished, and new channels of cultural and political engagement are facilitated as consumers become producers too. This does not mean, of course, that media power is no longer concentrated: the Leveson Inquiry in the UK has revealed starkly the consequences for many areas of public life of the abuse of power by the tabloid press and News International in particular. But this does not negate the argument about the consequences of the new flows and networks that are emerging with the developing use of the internet.

These consequences are varied and complex: with blogs, individuals have a voice and the potential to be heard by a vast audience. With posts, say on a forum, people can interact with one another, without the need for any intermediary. But social media (notably Twitter) are also key sources of news for journalists and others; they have become accommodated by 'old' media organisations and professionals.

Far from sweeping away the old, the new have become grafted on, making more complex the flows and practices. We still need journalists - to check sources, to perform for us a filtering role, and to contextualise and make sense of emerging 'facts' in a narrative or storyline or for the dissemination of content.

Not everything about the growing circulation of information is emancipatory. Whilst we can celebrate what Axel Bruns (2006) has called 'produsers' (as in the Arab spring uprisings), at the same time journalism is the first casualty of the internet - in that media organisations, to cut costs in the context of diminishing audiences and reduced advertising revenue, are spending less on journalism (Fenton 2010). So information is circulating as never before, but Yahoo et al. employ no journalists; facts are less frequently verified; analysis has become less professional or sophisticated; news organisations have less significance; arguments are less balanced as a cacophony of voices replaces professional reporting; and many users filter what is available in ways that lead to polarisation and enclaves, as opposed to some sort of public sphere or democratic engagement (Sunstein 2007).

The arrival of social media coincides temporally with a growth of accounting culture and an increasing emphasis on measuring targets and performance. It might be a consequence of the available information and technology that such indicators become more significant - illustrating how the tools, techniques or methods can take on a life of their own. Since the inception of broadcasting, about 90 years ago, the main measure has been the audience - a raw number, commonly with relevant socio-demographics. Such measures have been complemented by a few less significant measures, notably appreciation indices. With interactivity, however, a media organisation is engaged in a different exercise. It is no longer merely sending material out. In addition, it is receiving it back; and, on occasions, informing and facilitating horizontal communication between readers, listeners, or viewers, who can 'talk' with one another, without any need for an intervening media organisation.

For all broadcasters, the market is fragmenting. With the arrival of hundreds of television channels and radio stations, not to mention the almost limitless material on the internet, the era of media scarcity, for example with airwaves controlled by a state broadcaster, are over. In this context, the BBC World Service, despite its remarkable reputation forged during the Second World War and the Cold War, is rarely the sole or a major source of 'free' news and information - with Iran, Burma and China perhaps the exceptions.

In the case of the World Service this technological conjuncture, the arrival of interactivity, has coincided with fundamental changes of accountability. It was announced in 2010 that funding of the World Service would, from 2014, be transferred from the UK Government's Foreign \& Commonwealth Office to the licence fee payer - in other words, the UK public. Goals, targets and perform- 
ance indicators that have been relatively stable are likely to change - with 'impact' becoming more significant relative to 'reach' (the number who listen each week).

In this context, social media monitoring tools come to the fore - because of the vast scope of their data, its granularity, and its capacity to allow so many dimensions of the data to be cross tabulated. These new measurement instruments allow the World Service to know much more about the users of its services.

Social media constitute vast repositories of information about users - for example gender, physical attributes, geographical location, background, employment, educational history and social life - which is gleaned from images as well as text. Many are open and accessible archives of what used to be considered private thoughts and material. They hold giant databases of every social media conversation and posting, on a medium where the ethos is to publicise rather than conceal. Compared with, say, the mass observation archive (Hubble 2005), what is available - for social scientists as well as commercial and government bodies - is vast.

At the BBC, a variety of website and social media monitoring tools are in use. These include Adobe's SiteCatalyst, Facebook analytics, Social Bakers, and Sysomos MAP and Heartbeat. For the sake of brevity, I shall confine my comments to the last of these, the two Sysomos products. These provide tools to measure, monitor, understand and engage with social media. Sysomos MAP is a real-time monitoring and measurement tool. It provides (a) web analytics (analysing quantitatively the performance of a specific site, based on the behaviour of its users); (b) content aggregation (accumulating content from social media sites; and (c) sentiment analysis (understanding what the content means).

Social media analytics packages can track who users are and where they are. They generate metrics on volume, volume over time and segmentation by metrics (e.g. gender). Sysomos provides instant access to all social media conversations including blogs, social networks, microblogging services, forums, video sites and media sources. It provides constantly updated snapshots of social media conversations. It does this by analysing, in real-time and in 186 languages, what is being talked about, and the geo-demographics of those involved. It compares the performance of one site with another in relation to a specified topic, and generates the sort of data and representations shown in Figure 2.

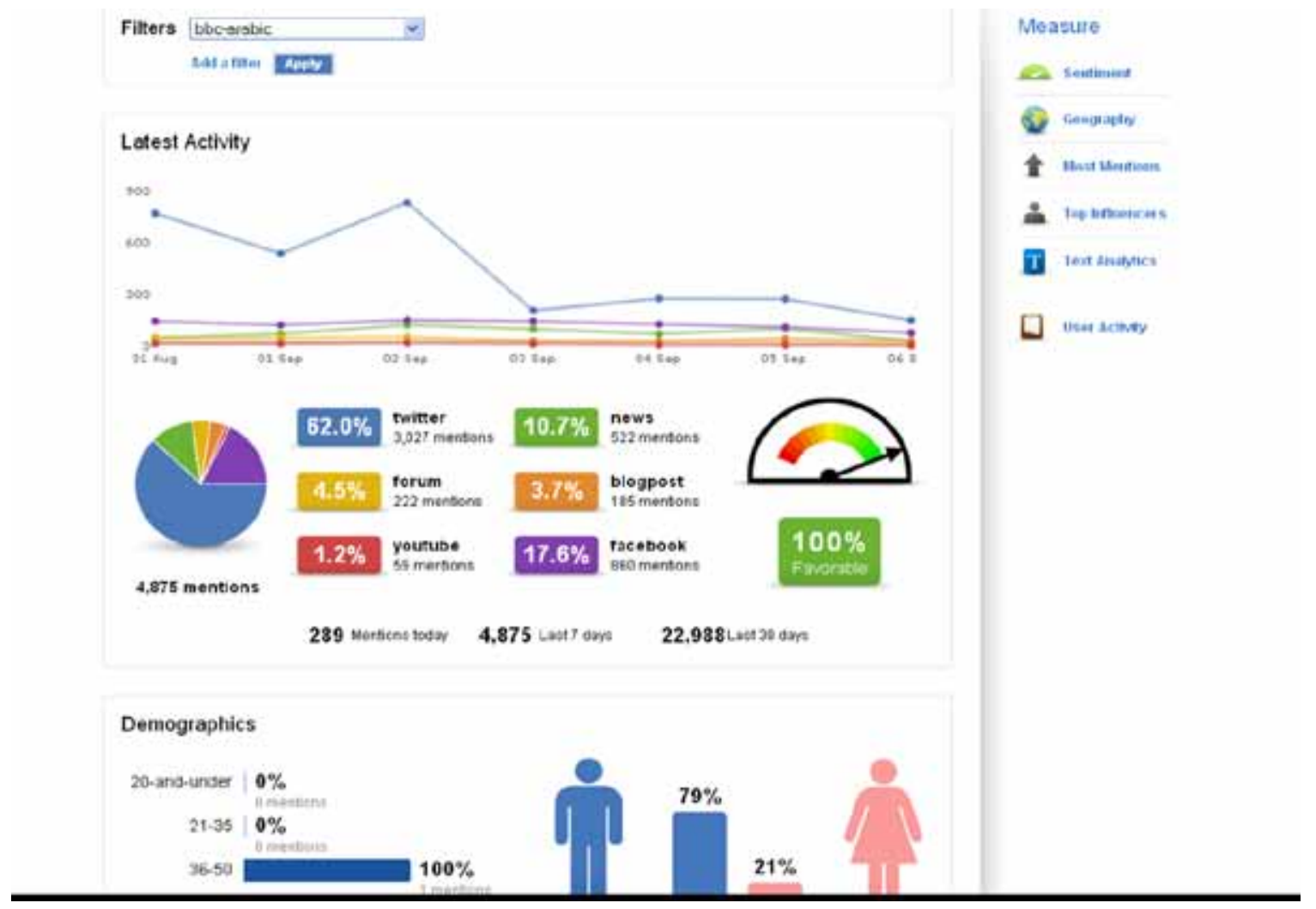

Figure 2: Sysomos MAP data for one week on BBC Arabic 
More than this, Sysomos' Heartbeat analyses the 'buzz' or sentiment that is being generated on the web around any event or story. By means of Natural Language Processing (NLP), an automated and crude form of content analysis, it develops measures of mood or sentiment analysis: it can see whether an issue or specific story is being commented on favourably or otherwise. So it measures not only the frequency with which people are discussing a news subject ('the buzz'), but also what they think of it; and whether they are 'recommending' it to others. It thus offers the prospect of measuring impact, whether the BBC is informing or even shaping debate. The capacities of the technology thus connect with emerging performance indicators.

Finally, it identifies the 'authority' of those who are engaging. This is calculated in different ways for different sites, but for Twitter it examines the number 'followed' and the number of 'followers', and from this calculates whether this is an influential person (one with many more followers than followed). Individuals are assigned a score of their 'influence'. Thus an attempt is made to identify those in authority and who are opinion leaders; which allows an organisation, in this case the BBC, to interact with them and thus enhance impact. One can drill down into the data represented in Figure 3, per (say) country, keyword, referrer and so on

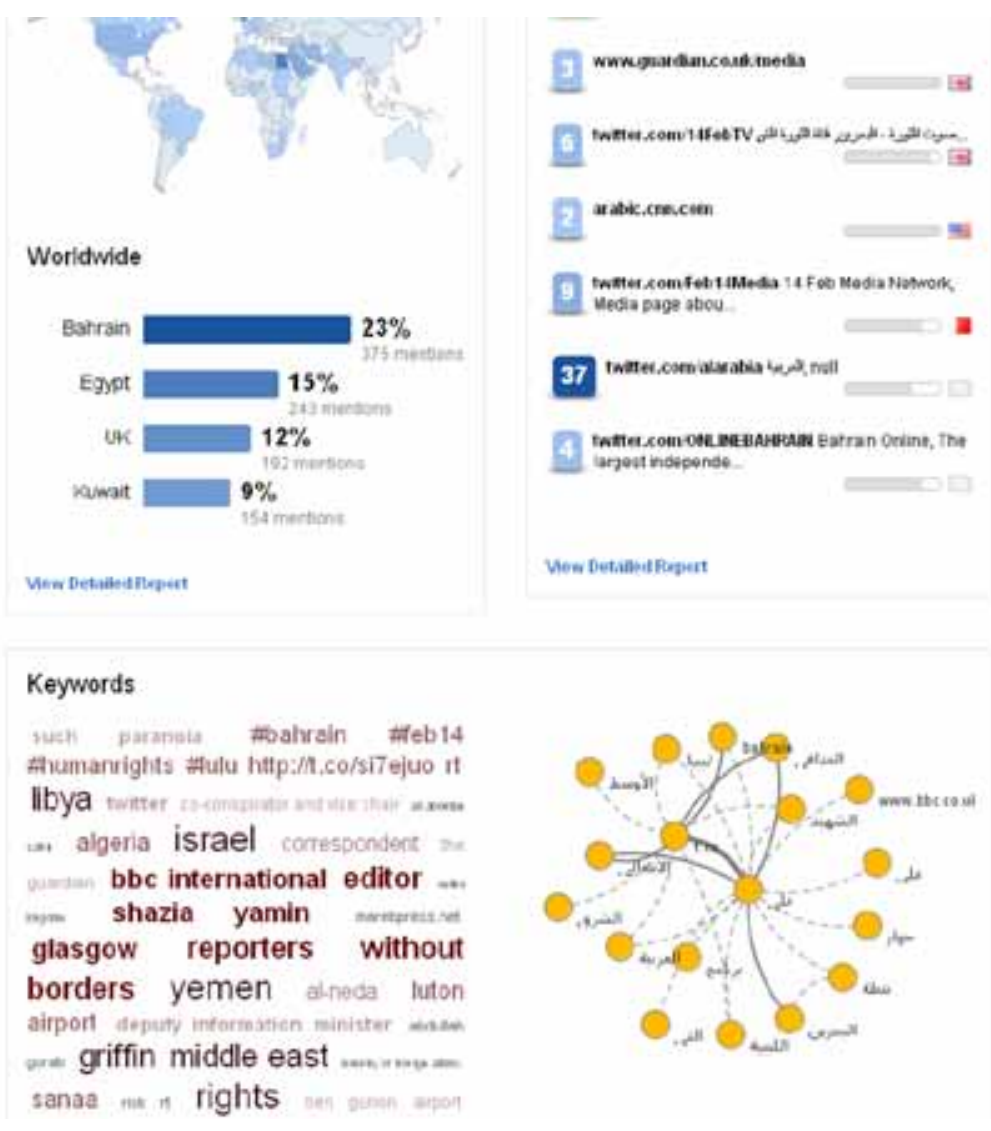

Figure 3: Sysomos Heartbeat: geo location, keywords, top influencers and key referrers

Sysomos, of course, is not without its limitations. Its tools have been developed for marketing purposes, and are more suitable for seeing how a new car model appeals to the fan community than for understanding how people are handling news. Whilst its language capacity is remarkable, it does not deal with hybrid languages (for example Spanglish); texting language; or other abbreviations. And it comes unstuck because some words have different meanings in Persian and Arabic languages. Perhaps the most significant limitation is of natural language processing - which fails to handle, for example, slang and irony. But what they can do and show is impressive.

Social media monitoring is big business - and not just in the field of marketing. In Summer 2011 the US Department of Defense announced a $\$ 42 \mathrm{~m}$ programme to fund research into monitoring social networks - to track the formation, development and spread of ideas, and identify misinformation and attempts to foment unrest (Rawsley 2011). So we can expect to see growth and technological developments in this area. 
It is clear that there is a new generation of experts in media research who are comfortable working with these tools. More than this, with user-friendly dashboards, regular reports can be created and circulated to key personnel in the BBC's 27 language services - who have become less reliant on the expertise and research of personnel in the research department (Audience Insights). Editors are now able to see - in real-time - how a given story, image, video, download, presenter or topic is being received by the audience. This allows far greater capacity to respond to user activity and preferences, and to tailor content accordingly. This, in turn, has implications for the organisation of journalists and newsrooms, and for the professional values of practitioners. The College of Journalism at the $\mathrm{BBC}$, for example, is constantly refining training courses on how to use social media; new guidelines are drawn up; and new practices become adopted. Thus we can see how the tools contribute to shaping organisational structures and professional practices.

\section{Conclusion: the Future for Sociology in an Era of Information Abundance}

Clearly such data is of interest outside the organisation. If it can be accessed (and on this count the BBC has been remarkably open), social researchers can explore communication processes in remarkable detail, huge volumes of data can be analysed productively and there are great possibilities for reporting, summarising and graphically representing the data. It would be hard to imagine such data being gathered in the academy. So here we see the tension: the abundant information offers rich possibilities for making sense of networks and communication, but scholars need access to the organisation's database and tools. This is a phenomenon that is far from confined to this case. It shows us how the growth of information has left the sociologist having to negotiate access to the data of powerful corporations if they are to enjoy the benefits of such information.

Sociology and social research today are less the preserve of academics in sociology departments in universities. Sociology has spread to adjacent subjects (social studies of science, business and management, media studies and more); whilst social research is now widespread beyond the academy. In 1960s and 1970s, major sociological studies, for example regarding educational attainment and social mobility, would be the focus of major press reporting and public debate. Today, think-tanks and cultural commentators, not to mention market researchers, are doing and reporting social research all the time. In this context, with the successful spreading of sociological approaches, but with a loss of control or even leadership of the field, sociologists are having to rethink what it is that is distinct about sociology and the work of sociologists. The availability of such vast repositories of data, together with tools for analysing it automatically (as well as by more traditional means), are good reasons to use it. This requires negotiation of access to the data, or in some cases its purchase (which can be expensive), the development of expertise in deploying new tools of analysis, and the development of new tools - tools which suit better the endeavour of sociology rather than market research as in my case study. Although such engagement with commercial and other organizations is not without its problems, the rich data that is available is in many cases the best way to understand emerging social formations.

\section{References}

Bell, Daniel. 1974. The Coming Post-Industrial Society. Harmondsworth: Penguin.

Benkler, Yochai. 2006. The Wealth of Networks: How Social Production Transforms Markets and Freedom. New Haven: Yale University Press.

Bowker, Geoffrey, and Susan Leigh Starr. 1999. Sorting Things Out: Classification and its Consequences. Cambridge: MIT Press.

Brown, Jonathan. 2010. Cashing in, the couple who dreamed up Tesco Clubcard. The Independent, 17 August. Accessed 14 February 2012. http://www.independent.co.uk/news/people/profiles/cashing-in-the-couple-who-dreamed-up-tescoclubcard-2054543.html.

Bruns, Axel. 2006. Blogs, Wikipedia, Second Life and Beyond: From Production to Produsage. New York: Peter Lang.

Burrows, Roger, and Mike Gane. 2006. Geodemographics, Software and Class. Sociology 40 (5): 793-812.

Castells, Manuel. 1996. The Rise of the Network Society (The Information Age: Economy, Society and Culture, Volume 1). Oxford: Blackwell.

Castells, Manuel. 1997. The Power of Identity (The Information Age: Economy, Society and Culture, Volume 2). Oxford: Blackwell.

Castells, Manuel. 1998. End of Millennium (The Information Age: Economy, Society and Culture, Volume 3). Oxford: Blackwell.

Castells, Manuel. 1999. An introduction to the information age. In The Media Reader: Continuity and Transformation, edited by Hugh Mackay and Tim O'Sullivan, 398-410. London: Sage.

Experian, 2010. Mosaic UK - the consumer classification of the United Kingdom. Nottingham: Experian.

Fenton, Natalie. 2010. Drowning or Waving? New Media, Journalism and Democracy. In New Media, Old News: Journalism and Democracy in the Digital Age, edited by Natalie Fenton, 3-16. London: Sage.

Graham, Stephen. 2004. The Software-Sorted City: Rethinking the 'Digital Divide'. In The Cybercities Reader, edited by Stephen Graham, 324-332. London: Routledge. 
Hartley, John. 2005. Creative Identities. In Creative Industries, edited by John Hartley, 106-16. Oxford: Blackwell. Hubble, Nick. 2005. Mass-Observation and Everyday Life. Basingstoke: Palgrave Macmillan.

Jenkins, Henry. 2006. Convergence Culture: Where Old and New Media Collide. New York: New York University Press.

Law, John, Evelyn Ruppert, and Mike Savage. 2011. The Double Social Life of Methods. CRESC Working Paper No. 95. Milton Keynes: Centre for Research on Socio-Cultural Change, The Open University. Accessed 14 February 2012. http://www.cresc.ac.uk/publications/the-double-social-life-of-methods.

Oudshoorn, Nelly, and Trevor Pinch, eds. 2003. How Users Matter: The Co-construction of Users and Technology. Cambridge: MIT Press.

Rawsley, Adam. 2011. Pentagon Wants a Social Media Propaganda Machine. Wired. 15 July. Accessed 15 February 2012. http://www.wired.com/dangerroom/2011/07/darpa-wants-social-media-sensor-for-propaganda-ops/.

Savage, Mike, Gaynor Bagnall, and Brian Longhurst. 2005. Globalization and Belonging. London: Sage.

Savage, Mike, and Roger Burrows. 2007. The Coming Crisis of Empirical Sociology. Sociology 41(5): 881-99.

Shirky, Clay. 2008. Here Comes Everybody: The Power of Organizing Without Organizations. Harmondsworth: Penguin.

Sunstein, Cass. 2007. Republic.com 2.0. Princeton: Princeton University Press.

Thrift, Nigel, and Shaun French. 2002. The Automatic Production of Space. Transactions of the Institute of British Geographers 27(3): 309-35.

Uricchio, William. 2004. Beyond the Great Divide: Collaborative Networks and the Challenge to Dominant Conceptions of Creative Industries. International Journal of Cultural Studies 7(1): 79-90.

Webster, Frank. 1995. Theories of the Information Society. London: Routledge.

Williams, Raymond. 1974. Television: Technology and Cultural Form. London: Fontana.

\section{About the Author}

Hugh Mackay

is Senior Lecturer at The Open University, UK and based in Wales. He is interested in the co-construction of technology and culture, in particular how users and producers shape technologies, and he researches new media. He recently completed an AHRC-funded Public Policy Fellowship on the implications of inter-activity for the organisation and practices of journalists at the BBC World Service; and, especially, the issues raised by the tools and techniques that are involved in measuring and accounting for interactivity in this context. He is a member of the joint Open University-Manchester University ESRC-funded CRESC. Under the auspices of CRESC, he has conducted qualitative research on the domestic uses of the internet, examining how internet use connects with everyday household life, which is being written up for a book to be published by Polity. 